\title{
Association between Number of Formed Embryos, Embryo Morphology and Clinical Pregnancy Rate after Intracytoplasmic Sperm Injection
}

\section{Associação entre número de embriões formados, morfologia embrionária e taxa de gravidez clínica após injeção intracitoplasmática de espermatozoides}

\author{
Caroline Mantovani da Luz ${ }^{1}$ Vanessa Silvestre Innocenti Giorgi ${ }^{1} \quad$ Marcela Alencar Coelho Neto ${ }^{1}$ \\ Wellington de Paula Martins ${ }^{1}$ Rui Alberto Ferriani ${ }^{1}$ Paula Andrea Navarro ${ }^{1}$ \\ 1 Obstetrics and Gynecology Department, Ribeirão Preto Medicine
School, Universidade de São Paulo (DGO-FMRP-USP), Ribeirão Preto,
São Paulo, Brazil \\ Rev Bras Ginecol Obstet 2016;38:465-470.

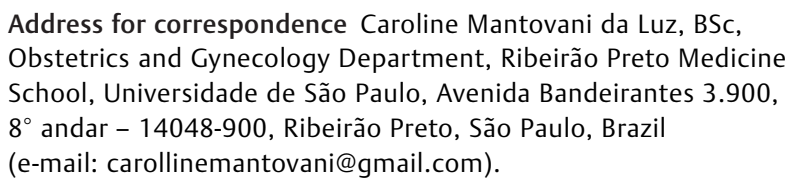

Address for correspondence Caroline Mantovani da Luz, BSc, Obstetrics and Gynecology Department, Ribeirão Preto Medicine School, Universidade de São Paulo, Avenida Bandeirantes 3.900, $8^{\circ}$ andar - 14048-900, Ribeirão Preto, São Paulo, Brazil (e-mail: carollinemantovani@gmail.com).

\begin{abstract}
Keywords

- number of embryos

- morphological evaluation

- embryo quality

- clinical pregnancy

- ICSI

Introduction Infertility has a high prevalence in the general population, affecting $\sim 5$ to $15 \%$ of couples in reproductive age. The assisted reproduction techniques (ART) include in vitro manipulation of gametes and embryos and are an important treatment indicated to these couples. It is well accepted that the implantation rate is positively influenced by the morphology of transferred embryos. However, we question if, apart from the assessment of embryo morphology, the number of produced embryos per cycle is also related to pregnancy rates in the first fresh transfer cycle.

Purpose To evaluate the clinical pregnancy rate according to the number of formed embryos and the transfer of top quality embryos (TQEs).

Methods In a retrospective cohort study, between January 2011 and December 2012, we evaluated women who underwent intracytoplasmic sperm injection (ICSI), aged $<40$ years, and with at least 1 formed embryo fresh transferred in cleavage stage. These women were stratified into 3 groups according to the number of formed embryos (1 embryo, 2-3 and $\geq 4$ embryos). Each group was divided into 2 subgroups according to the presence or not of at least 1 transferred TQE (1 with TQE; 1 without TQE; 2-3 with TQE, 2-3 without TQE; $\geq 4$ with TQE; $\geq 4$ without TQE). The clinical pregnancy rates were compared in each subgroup based on the presence or absence of at least one transferred TQE.

Results During the study period, 636 women had at least one embryo to be transferred in the first fresh cycle (17.8\% had 1 formed embryo [32.7\% with TQE versus $67.3 \%$ without TQE], $42.1 \%$ of women had $2-3$ formed embryos [ $55.6 \%$ with TQE versus $44.4 \%$ without TQE], and $40.1 \%$ of patients had $\geq 4$ formed embryos [ $73.7 \%$ with TQE versus $26.3 \%$ without TQE]). The clinical pregnancy rate was significantly higher in the subgroup with $\geq 4$ formed embryos with at least 1 transfered TQE (45.2\%) compared with the subgroup without TQE (28.4\%).
\end{abstract}

received

May 25, 2016

accepted

July 25, 2016

published online

September 21, 2016
DOI http://dx.doi.org/

10.1055/s-0036-1592338. ISSN $0100-7203$.
Copyright $@ 2016$ by Thieme Publicações License terms

Ltda, Rio de Janeiro, Brazil 


\section{Resumo}

\author{
Palavras-chave \\ - número de \\ embriões \\ - avaliação \\ morfológica \\ - qualidade \\ embrionária \\ - gravidez clínica \\ - ICSI
}

Conclusions Having at least two available embryos and at least one TQE for embryo transfer are predictors of the pregnancy rates.

Introdução A infertilidade tem uma alta prevalência na população geral, afetando $\sim 5$ a 15\% dos casais em idade reprodutiva. As técnicas de reprodução assistida (TRA) incluem a manipulação in vitro de gametas e embriões e são um importante tratamento indicado para esses casais. Sabe-se que a taxa de implantação é positivamente influenciada pela morfologia dos embriões transferidos. No entanto, questiona-se, se além da avaliação da morfologia do embrião, o número de embriões produzidos por ciclo também está relacionado com as taxas de gravidez do primeiro ciclo de transferência fresco.

Objetivo Avaliar a taxa de gravidez clínica de acordo com o número de embriões formados e a transferência de embrião com ótima morfologia (EOM).

Métodos Em um estudo de coorte retrospectivo, entre janeiro de 2011 e dezembro de 2012, avaliamos mulheres submetidas a ICSI com idade $<40$ anos e com pelo menos um embrião formado e transferido a fresco em estágio de clivagem. Estas mulheres foram estratificadas em 3 grupos de acordo com o número de embriões formados (1 embrião, $2-3$ e $\geq 4$ embriões). Cada grupo foi subdividido em 2 subgrupos de acordo com a presença ou não de EOM transferido (1 com EOM; 1 sem EOM; 2-3 com EOM; 2-3 sem EOM; $\geq 4$ com EOM; $\geq 4$ sem EOM). As taxas de gravidez clínica foram comparadas em cada subgrupo segundo a presença ou não de pelo menos um EOM transferido.

Resultados Durante o período do estudo, 636 mulheres tiveram pelo menos 1 embrião para ser transferido no primeiro ciclo a fresco (17,8\% possuíram 1 embrião formado [32,7\% com EOM versus 67,3\% sem EOM], 42,1\% das mulheres apresentaram 2-3 embriões formados [55,6\% com EOM versus 44,4\% sem EOM], e 40,1\% das pacientes formaram $\geq 4$ embriões [73,7\% com EOM versus $26,3 \%$ sem EOM]). A taxa de gravidez clínica foi significativamente maior no subgrupo com $\geq 4$ embriões formados com transferência de pelo menos 1 EOM (45,2\%) comparando-se ao subgrupo sem EOM (28,4\%).

Conclusões Ter pelo menos dois embriões e pelo menos um EOM para transferência são fatores preditivos da taxa de gravidez.

\section{Introduction}

Infertility, defined as the absence of conception after a year of unprotected sexual activity, has a high prevalence in the general population, affecting $\sim 5$ to $15 \%$ of couples in reproductive age. ${ }^{1,2}$ The assisted reproduction techniques (ART) are procedures that include in vitro manipulation of gametes (eggs and sperm) and embryos for the purpose of establishing a pregnancy. $^{3,4}$ In developed countries, $\sim 5 \%$ of all births are resultant of ART, which is an important treatment indicated to infertile couples. ${ }^{5,6}$ For ART, women are submitted to controlled ovarian stimulation (COS) with artificial hormones. ${ }^{7-9}$ This strategy aims to obtain a greater number of oocytes and embryos, enabling an increase of cumulative pregnancy rate per cycle. ${ }^{10,11}$ However, we question whether the total number of formed embryos has an influence in the pregnancy rate in the first fresh transfer cycle.

The conventional morphological evaluation is used as an indirect method for checking the quality and the potential of embryonic development; however, the analyzed parameters still diverge. ${ }^{12,13}$ To homogenize the conventional morphological evaluation, experts in the issue created the Istanbul Consensus. ${ }^{13}$ Based on this consensus, a top quality embryo (TQE) on the second day of development (D2) has 4 cells Grade 1 (symmetrical blastomeres, with less than $10 \%$ of fragmentation and without multinucleation), and on the third day of development (D3), has 8 cells Grade $1 .{ }^{13}$ Some studies suggest that the implantation rate is positively influenced by the morphology of transferred embryos: the TQEs, for example, present greater potential for implantation and to generate live births compared with embryos with worse morphology. ${ }^{12-14}$

Thus, we question if, apart from the assessment of embryo morphology, the number of produced embryos per cycle is also related to pregnancy rates in the first fresh transfer cycle. Elucidating the impact of the number of formed embryos together with embryonic morphology can help determine the gestational outcomes, adjusting the expectations of patients and physicians. Therefore, the aim of this study 
was to compare the clinical pregnancy rate in the first fresh transfer cycle of women who formed and transferred at least 1 embryo, divided into 6 groups according to the number of formed embryos $(1,2-3$ and $\geq 4)$ and transfer or not of at least $1 \mathrm{TQE}$ in D2 or D3.

\section{Methods}

This retrospective cohort study evaluated all women who underwent COS for intracytoplasmic sperm injection (ICSI) at the fertility clinic of the Hospital das Clínicas da Faculdade de Medicina de Ribeirão Preto, Universidade de São Paulo, Brazil, between January 2011 and December 2012. All data were obtained from medical records by one author (MACN). The study protocol was approved by the Institutional Review Board (\# 9682/2012), which waived the requirement for additional informed consent due to the retrospective nature of the study.

Women younger than 40 years submitted to COS for ICSI who had at least 1 embryo formed and transferred in cleavage stage in the first fresh cycle were considered eligible. If the patient had been subjected to more than one COS cycle during this period, only data from the first cycle were included in the analysis. All women were followed-up until a negative pregnancy test or until the first ultrasound performed two to three weeks after the positive pregnancy test.

Patients were stratified into 3 groups according to the number of formed embryos in cleavage stage ( 1 embryo; $2-3$ embryos and $\geq 4$ embryos). Each group was subdivided into two subgroups (with or without TQE), transferred in the first fresh cycle ( 1 with TQE; 1 without TQE; $2-3$ with TQE, 2-3 without TQE; $\geq 4$ with TQE; $\geq 4$ without TQE). Patients who had formed two or more embryos transferred only two embryos in the fresh cycle.

All included patients had menstruation programmed with oral combined contraceptives, starting during the previous menstrual cycle. The COS was started five days after the discontinuation of oral contraceptives. The transvaginal ultrasound was performed on the first day of the COS to assess the endometrial pattern and rule out the presence of ovarian cysts. These may interfere in the response to exogenous gonadotropins or in the monitoring of follicle growth by ultrasound. ${ }^{15}$

Three COS protocols could be used: in the standard long protocol, the use of gonadotropin-releasing hormone $(\mathrm{GnRH})$ agonists (leuprolide acetate $0.5 \mathrm{mg} /$ day) was initiated during the luteal phase of the previous cycle, followed by gonadotropin (150-300 UI/day) during the first days of COS. Subsequently, the daily dose of gonadotropin was adjusted according to follicular growth.

In the flexible antagonist protocol, gonadotropin (150$300 \mathrm{IU} /$ day) was administrated during the first 6 days of COS, with a daily dose adjusted according to follicular growth. Gonadotropin-releasing hormone antagonists (cetrorelix or ganirelix $0.25 \mathrm{mg} /$ day) were administered on the day that the average diameter of the largest follicle was $\geq 14 \mathrm{~mm}$.

The minimal stimulation protocol (clomiphene citrate [CC] plus gonadotropins and GnRH antagonist) was offered to some women with low antral follicle count (AFC; AFC $\leq 6) .{ }^{15}$ The CC (100 mg/day) was administered during the first 5 days of COS, and gonadotropins (150 UI/day) were administered on days 2 and 4, and daily from day 6 on. The GnRH antagonist (cetrorelix or ganirelix $0.25 \mathrm{mg} /$ day) was administered on the day that the average diameter of the largest follicle was $\geq 14 \mathrm{~mm}$.

The recombinant human chorionic gonadotrophin (hCG [250 mcg, Ovidrel ${ }^{\circledR}$, Serono, Brazil]), or urinary hCG $(10,000$ IU Choriomon ${ }^{\circledR}$, Meizler, Brazil) was administered when at least 1 follicle with a mean diameter of $18 \mathrm{~mm}$ was present. Oocytes were obtained 34-36 hours after administration of the recombinant hCG, and the luteal phase was maintained by administration of micronized progesterone ( $600 \mathrm{mg} /$ day).

The mature oocytes were subjected to ICSI and cultured individually. Fertilization was defined as the presence of two pronuclei and two polar bodies. Embryo quality was evaluated $\sim 43$ and 45 hours after ICSI (second day of embryonic development), based on the number and symmetry of blastomeres' percentage of fragmentation and presence or absence of multinucleation. If the embryo transfer was not performed in D2, embryo quality was analyzed $\sim 67$ to 69 hours after ICSI (D3). ${ }^{13}$

The D2 embryos with 4 symmetrical blastomeres, normal sized, with $<10 \%$ fragmentation, and without multinucleation were considered top quality. ${ }^{13}$ Embryos on the third day of development and with 8 symmetrical blastomeres, normal sized, with $<10 \%$ of fragmentation, and without multinucleation were also considered top quality. ${ }^{13}$

The clinical pregnancy rate per cycle was defined as the number of patients that presented an ultrasound (4 to 5 weeks after transfer) with embryo heartbeat divided by the number of cycles $\times 100$.

The primary endpoint of this study was the rate of clinical pregnancy. The following parameters were assessed: age, weight, height, body mass index (BMI), duration and etiology of infertility, antral follicle count (AFC), protocol used for COS, number of retrieved oocytes, number of captured metaphase II (MII) oocytes, number of formed embryos, of transferred embryos and of TQEs. All data were obtained from medical records.

\section{Statistical Analyses}

The study size was defined as the total number of eligible patients (women younger than 40 years submitted to COS for ICSI who had at least 1 embryo formed and transferred in cleavage stage in the first fresh cycle) during the study period.

First, women were stratified into 3 groups according to the number of cleavage stage formed embryos (1 embryo; 2-3 embryos and $\geq 4$ embryos). Then, each group was divided into two subgroups according to the presence or absence of at least one transferred TQE; clinical pregnancy rates and other variables were compared in each group as described below.

The normal distribution of continuous variables was analyzed using the Kolmogorov-Smirnov test. Continuous variables with normal distribution were presented as mean \pm standard deviation (SD) and compared between the groups with and without TQE by unpaired $t$-test. Continuous variables without normal distribution were presented as 
Table 1 Characteristics of the included participants depending on the number of available embryos and on the presence of embryo(s) considered as having top morphologic criteria

\begin{tabular}{|c|c|c|c|c|c|c|c|c|c|}
\hline \multirow{2}{*}{$\frac{\text { Groups }}{\text { Subgroups }}$} & \multicolumn{3}{|l|}{1 embryo } & \multicolumn{3}{|l|}{ 2-3 embryos } & \multicolumn{3}{|l|}{$\geq 4$ embryos } \\
\hline & Without TQE & With TQE & $p$ & Without TQE & With TQE & $p$ & Without TQE & With TQE & $p$ \\
\hline$N$ & 76 & 37 & & 119 & 149 & & 67 & 188 & \\
\hline \multicolumn{10}{|l|}{ Parameter } \\
\hline Age & $35.7 \pm 4.4$ & $34.7 \pm 4.7$ & 0.27 & $34.6 \pm 4.1$ & $34.0 \pm 4.5$ & 0.26 & $33.4 \pm 3.7$ & $33.4 \pm 4.1$ & 0.91 \\
\hline Weight & $69.1 \pm 11.8$ & $70.7 \pm 15.7$ & 0.60 & $64.8 \pm 12.1$ & $67.1 \pm 12.8$ & 0.15 & $65.2 \pm 12.0$ & $65.2 \pm 10.7$ & 0.98 \\
\hline Height & $1.65 \pm 0.06$ & $1.65 \pm 0.06$ & 0.70 & $1.63 \pm 0.07$ & $1.64 \pm 0.06$ & 0.42 & $1.64 \pm 0.06$ & $1.63 \pm 0.06$ & 0.16 \\
\hline BMI & $25.5 \pm 4.3$ & $25.4 \pm 5.2$ & 0.73 & $24.4 \pm 4.1$ & $25.1 \pm 4.4$ & 0.23 & $24.3 \pm 4.1$ & $24.6 \pm 3.7$ & 0.53 \\
\hline AFC & $6[4-11]$ & $7[4-14]$ & 0.49 & $11[7-15]$ & $9[6-16]$ & 0.54 & 16 [11-25] & 16 [11-21] & 0.31 \\
\hline Duration of infertility & 70 [43-105] & $58[41-87]$ & 0.33 & $58[36-88]$ & $54[28-77]$ & 0.23 & 62 [37-91] & $51[32-77]$ & 0.14 \\
\hline Cause of infertility & & & 0.15 & & & 0.68 & & & 0.68 \\
\hline Ovulatory & $4(5 \%)$ & $1(3 \%)$ & & $8(7 \%)$ & $11(7 \%)$ & & $1(1 \%)$ & $7(4 \%)$ & \\
\hline Endometriosis & $13(17 \%)$ & $5(14 \%)$ & & $13(11 \%)$ & $24(16 \%)$ & & $9(13 \%)$ & $21(11 \%)$ & \\
\hline Male & $21(28 \%)$ & $4(11 \%)$ & & 34 (29\%) & $39(26 \%)$ & & $15(22 \%)$ & $58(31 \%)$ & \\
\hline Tubal & $5(7 \%)$ & $2(5 \%)$ & & $15(13 \%)$ & $14(9 \%)$ & & $5(7 \%)$ & $14(7 \%)$ & \\
\hline Combined & $25(33 \%)$ & 22 (59\%) & & 39 (33\%) & $53(36 \%)$ & & 27 (40\%) & $69(37 \%)$ & \\
\hline Unexplained & $8(11 \%)$ & $3(8 \%)$ & & $10(8 \%)$ & $8(5 \%)$ & & 10 (15\%) & $20(11 \%)$ & \\
\hline $\begin{array}{l}\text { Ovarian } \\
\text { stimulation } \\
\text { protocol }\end{array}$ & & & 0.96 & & & 0.79 & & & 0.10 \\
\hline $\mathrm{FSH}+\mathrm{Ant}$ & 45 (59\%) & 22 (59\%) & & 79 (66\%) & $101(68 \%)$ & & $51(76 \%)$ & $149(79 \%)$ & \\
\hline $\mathrm{FSH}+\mathrm{Ago}$ & $12(16 \%)$ & $5(14 \%)$ & & $30(25 \%)$ & $33(22 \%)$ & & $13(19 \%)$ & $38(20 \%)$ & \\
\hline $\mathrm{CC}+\mathrm{FSH}+\mathrm{Ant}$ & $19(25 \%)$ & $10(27 \%)$ & & $10(8 \%)$ & $15(10 \%)$ & & $3(4 \%)$ & $1(1 \%)$ & \\
\hline
\end{tabular}

Abbreviations: AFC, antral follicle count; BMI, body mass index; CC, clomiphene citrate; $\mathrm{FSH}^{+} \mathrm{Ago}$, agonist protocol with follicle-stimulating hormone; $\mathrm{FSH}^{+} \mathrm{Ant}$, antagonist protocol with follicle-stimulating hormone; $\mathrm{N}$, number of women analyzed; TQE, top quality embryo. Note: Data presented as mean \pm SD, median [interquartile range], or number (proportion).

median (interquartile range), and comparisons were made by Mann-Whitney test. Binary data were presented as a ratio (\%) and compared using Fisher's exact test. The level of significance was defined as $p<0.05$. All statistical analyzes were performed using the SPSS software (version 18.0, SPSS Inc., Chicago, IL, US). For the additional analysis, we determined the power of the study to detect a difference of $10 \%$ in clinical pregnancy rates among women with one embryo; 2-3 embryos and $\geq 4$ embryos.

\section{Results}

Within the study period, 792 women were subjected to ICSI. Among these women, 130 patients had no available embryos after oocyte retrieval, 19 did not transfer fresh embryos, 1 patient had the embryo culture extended to blastocyst, and 6 had no full records of morphological evaluation in the medical records. The 636 remaining patients (who had at least one embryo to be transferred in the same cycle) were followed until a negative pregnancy test or until the transvaginal ultrasound (TVU), four to five weeks after transfer.

Of the 636 patients included in the study, $17.8 \%$ had 1 available embryo (32.7\% with TQE versus $67.3 \%$ without TQE), $42.1 \%$ of women had 2-3 available embryos (55.6\% with TQE versus $44.4 \%$ without TQE), and $1 \%$ of patients had $\geq 4$ available embryos (73.7\% with TQE versus $26.3 \%$ without TQE).

Within each group $(1,2-3$ and $\geq 4)$, there were no statistically significant differences in the patients' age, weight, height, BMI, cause of infertility, duration of infertility, AFC, COS protocols (-Table 1), number of retrieved oocytes and MII oocytes compared with women who had transferred or not at least $1 \mathrm{TQE}$. However, the number of embryos was significantly higher in patients in groups 2-3 and $\geq 4$ embryos with TQE compared with the groups without TQE (-Table 2).

Among women who had and transferred only 1 embryo, there was no difference in the pregnancy rate compared with women with TQE (16.2\%) and without TQE (9.2\%). Among those who had 2-3 available embryos, 33.5\% of women with TQE and $30.2 \%$ of women without TQE became pregnant, also showing no significant difference between groups. Of the patients who had 4 or more available embryos, $45.2 \%$ of women with TQE and $28.3 \%$ of women without TQE became pregnant. The clinical pregnancy rate was significantly higher in the subgroup with $\geq 4$ available embryos with at least 1 transferred TQE ( $\geq 4$ with TQE) compared to the subgroup without TQE ( $\geq 4$ without TQE) (-Table 2 ).

The present study presented a test power of $\sim 70 \%$ to detect a difference of $20 \%$ in clinical pregnancy rates between 
Table 2 Main outcomes depending on the number of available embryos and on the presence of embryo(s) considered as having top morphologic criteria

\begin{tabular}{|c|c|c|c|c|c|c|c|c|c|}
\hline \multirow{2}{*}{$\begin{array}{l}\text { Groups } \\
\text { Subgroups }\end{array}$} & \multicolumn{3}{|l|}{1 embryo } & \multicolumn{3}{|l|}{ 2-3 embryos } & \multicolumn{3}{|l|}{$\geq 4$ embryos } \\
\hline & $\begin{array}{l}\text { Without } \\
\text { TQE }\end{array}$ & With TQE & $p$ & Without TQE & With TQE & $p$ & Without TQE & With TQE & $p$ \\
\hline $\mathrm{N}$ & 76 & 37 & & 119 & 149 & & 67 & 188 & \\
\hline \multicolumn{10}{|l|}{ Parameter } \\
\hline Retrieved oocytes & $2[1-3]$ & $2[1-4]$ & 0.86 & $5[4-7]$ & $5[4-7]$ & 0.68 & $10[7-12]$ & $10[8-14]$ & 0.25 \\
\hline MII retrieved & $2[1-3]$ & $1[1-3]$ & 0.45 & $4[3-6]$ & $4[3-5]$ & 0.42 & $7[6-10]$ & $9[6-11]$ & 0.07 \\
\hline Formed embryos & $1[1-1]$ & $1[1-1]$ & 1.00 & $2[2-2]$ & $2[2-3]$ & $<0.01^{*}$ & $4[4-6]$ & $5[4-7]$ & $<0.01^{*}$ \\
\hline Transferred embryos & $1[1-1]$ & $1[1-1]$ & 1.00 & $2[2-2]$ & $2[2-2]$ & 0.94 & $2[2-2]$ & $2[2-2]$ & 0.64 \\
\hline Clinical pregnancy & 7 (9.2\%) & $6(16.2 \%)$ & 0.35 & $36(30.2 \%)$ & $50(33.5 \%)$ & 0.60 & 19 (28.3\%) & 85 (45.2\%) & $0.02^{*}$ \\
\hline
\end{tabular}

Abbreviations: MII, metaphase II; N, number of women analyzed; p, p-value; TQE, top quality embryo. ${ }^{*} p$ statistically significant. Note: Data presented as median [interquartile range], or number (proportion).

patients with and without transferred TQE and only 1 available embryo; $40 \%$ for the subgroups that had $2-3$ available embryos; and $30 \%$ for the subgroups that had $\geq 4$ available embryos.

\section{Discussion}

Our study evidenced that, during ART, the embryonic morphological evaluation, in the second or third day of development, is an important factor involved in the prognosis of clinical pregnancy, especially in women who had four or more embryos. In the group with $\geq 4$ available embryos, there was an increase of $\sim 17 \%$ in clinical pregnancy rates in the subgroup of patients that transferred at least $1 \mathrm{TQE}$ in the first fresh transfer cycle (45\%) compared with those women who had no TQE (28\%) transferred. Among the many plausible conditions to influence pregnancy rates after ART, the number of retrieved oocytes, the number of available embryos and the number of transferred TQEs seem to be the most important factors of reproductive prognosis. ${ }^{16-20}$ However, there are few studies evaluating the relationship between pregnancy rate and live birth rate and the number and morphological quality of the embryos concomitantly. In women over 40 years, Opsahl et $\mathrm{al}^{21}$ found that patients who had less than 4 embryos presented lower chances of pregnancy than those who formed $\geq 4$; however; this study did not take into account the morphology of the embryos. ${ }^{21}$ Corroborating our findings, Van Loendersloot et $\mathrm{a}^{22}$ suggested that the number of available embryos and their morphological quality in the third day of culture should be important factors in the development of a model to predict the probability of pregnancy after in vitro fertilization (IVF). ${ }^{22}$

In the group with 1 embryo, the difference in the clinical pregnancy rates among the subgroups with TQE (16.2\%) and without TQE (9.2\%) was $7 \%$. And in the group with $2-3$ available embryos, the difference in the clinical pregnancy rates among subgroups with TQE (33.5\%) and without TQE (30.2\%) was 3.3\%. Despite the fact that these differences were not statistically significant, this study did not have the adequate test power to confirm the findings, and studies with larger sample sizes are necessary to evaluate whether patients who present less than 4 embryos have their pregnancy rates influenced or not by the morphology of transferred embryos.

Among several analyzed secondary outcomes, in groups with the formation of 2-3 embryos and $\geq 4$ embryos, the number of embryos differed between groups with and without TQEs. In the group with $\geq 4$ embryos, $73.7 \%$ of women had TQEs, and just $26.3 \%$ did not. These findings suggest that women who generate a greater number of embryos have a greater potential to form TQEs. ${ }^{23}$ The other evaluated secondary endpoints showed no statistically significant difference between the subgroups, further reinforcing the findings of the study, excluding the interference of these parameters on the primary endpoint (clinical pregnancy rate).

Previous researches showed that the quality and size of the embryo cohort allow the selection of TQEs for transfer in the fresh cycle and, subsequently, in frozen cycles, thus influencing the cumulative pregnancy rate. ${ }^{21,24}$ However, both factors, number and quality of embryos together, can be a valuable tool in predicting the probability of pregnancy after ICSI, adjusting the expectations of patients and physicians.

Since this is a retrospective study, the information was obtained exclusively from medical records. Another important point is the relatively small sample size in each subgroup, so that larger studies are important to confirm our findings and investigate the influence of embryo morphology on the embryos' cleavage stage in women that had fewer than 4 embryos per cycle of IVF/ICSI. Since in our analysis we included only data from the first cycle of each patient, it is not possible to extrapolate whether the cumulative clinical pregnancy rate, per cycle or time, is different in women with or without TQEs.

This study allows to more accurately establish the chances of clinical pregnancy per cycle for patients under 40 years who have at least 1 embryo in the first fresh transfer cycle. This information is useful when counseling couples in order to determine the gestational outcomes, adjusting the expectations of doctors and patients. 
In conclusion, among women undergoing COS for ICSI, women that had four or more embryos and transferred at least one TQE in the first fresh transfer cycle have higher rates of clinical pregnancy compared with those of women without TQEs. Thus, we found that the number of embryos per cycle and the quality of embryos transferred are important prognostic factors in ART.

\section{Acknowledgments}

The authors are grateful to Universidade de São Paulo (USP), the Fundação de Apoio ao Ensino, Pesquisa e Assistência do Hospital das Clínicas da Faculdade de Medicina de Ribeirão Preto (Foundation for Support in Teaching, Research and Assistance - FAEPA), and the Conselho Nacional de Desenvolvimento Científico e Tecnológico (Brazilian National Council for Research and Development (- CNPq) for their financial support.

\section{References}

1 Gnoth C, Godehardt E, Frank-Herrmann P, Friol K, Tigges J, Freundl G. Definition and prevalence of subfertility and infertility. Hum Reprod 2005;20(5):1144-1147

2 Boivin J, Bunting L, Collins JA, Nygren KG. International estimates of infertility prevalence and treatment-seeking: potential need and demand for infertility medical care. Hum Reprod 2007;22(6): 1506-1512

3 Zegers-Hochschild F, Adamson GD, de Mouzon J, et al; International Committee for Monitoring Assisted Reproductive Technology; World Health Organization. International Committee for Monitoring Assisted Reproductive Technology (ICMART) and the World Health Organization (WHO) revised glossary of ART terminology, 2009. Fertil Steril 2009;92(5):1520-1524

4 Macaluso M, Wright-Schnapp TJ, Chandra A, et al. A public health focus on infertility prevention, detection, and management. Fertil Steril 2010;93(1):16.e1-16.e10

5 Sunderam S, Kissin DM, Crawford SB, et al; Centers for Disease Control and Prevention (CDC). Assisted Reproductive Technology Surveillance - United States, 2012. MMWR Surveill Summ 2015; 64(6):1-29

6 Kupka MS, Ferraretti AP, de Mouzon J, et al; European IVFMonitoring Consortium, for the European Society of Human Reproduction and Embryology. Assisted reproductive technology in Europe, 2010: results generated from European registers by ESHRE. Hum Reprod 2014;29(10):2099-2113

7 Queenan JT Jr, Whiman-Elia G. An appreciation of modern ART. Clin Obstet Gynecol 2000;43(4):942-957

8 Al-Inany HG, Youssef MA, Ayeleke RO, Brown J, Lam WS, Broekmans FJ. Gonadotrophin-releasing hormone antagonists for assisted reproductive technology. Cochrane Database Syst Rev 2016;4:CD001750

9 Shrestha D, La X, Feng HL. Comparison of different stimulation protocols used in in vitro fertilization: a review. Ann Transl Med 2015;3(10):137
10 Revelli A, Pettinau G, Basso G, et al. Controlled Ovarian Stimulation with recombinant-FSH plus recombinant-LH vs. human Menopausal Gonadotropin based on the number of retrieved oocytes: results from a routine clinical practice in a real-life population. Reprod Biol Endocrinol 2015;13:77

11 Fauser BC, Diedrich K, Devroey P; Evian Annual Reproduction Workshop Group 2007. Predictors of ovarian response: progress towards individualized treatment in ovulation induction and ovarian stimulation. Hum Reprod Update 2008;14(1):1-14

12 Weitzman VN, Schnee-Riesz J, Benadiva C, Nulsen J, Siano L, Maier D. Predictive value of embryo grading for embryos with known outcomes. Fertil Steril 2010;93(2):658-662

13 Alpha Scientists in Reproductive Medicine and ESHRE Special Interest Group of Embryology. The Istanbul consensus workshop on embryo assessment: proceedings of an expert meeting. Hum Reprod 2011;26(6):1270-1283

14 Racowsky C, Stern JE, Gibbons WE, Behr B, Pomeroy KO, Biggers JD. National collection of embryo morphology data into Society for Assisted Reproductive Technology Clinic Outcomes Reporting System: associations among day 3 cell number, fragmentation and blastomere asymmetry, and live birth rate. Fertil Steril 2011; 95(6):1985-1989

15 Martins WP, Vieira CV, Teixeira DM, Barbosa MA, Dassunção LA, Nastri CO. Ultrasound for monitoring controlled ovarian stimulation: a systematic review and meta-analysis of randomized controlled trials. Ultrasound Obstet Gynecol 2014;43(1): 25-33

16 Wood C, McMaster R, Rennie G, Trounson A, Leeton J. Factors influencing pregnancy rates following in vitro fertilization and embryo transfer. Fertil Steril 1985;43(2):245-250

17 Check JH, Nowroozi K, Choe J, Dietterich C. Influence of endometrial thickness and echo patterns on pregnancy rates during in vitro fertilization. Fertil Steril 1991;56(6):1173-1175

18 Baker MJ, Denton TT, Herr C. An explanation for why it is difficult to form slush nitrogen from liquid nitrogen used previously for this purpose. Cryobiology 2013;66(1):43-46

19 Abdullah UH, Lalani S, Syed F, Arif S, Rehman R. Association of Vitamin D with outcome after intra cytoplasmic sperm injection. J Matern Fetal Neonatal Med 2016:1-4 [Epub ahead of print]

20 Luke B, Brown MB, Stern JE, Jindal SK, Racowsky C, Ball GD. Using the Society for Assisted Reproductive Technology Clinic Outcome System morphological measures to predict live birth after assisted reproductive technology. Fertil Steril 2014; 102(5):1338-1344

21 Opsahl MS, Blauer KL, Black SH, Lincoln SR, Thorsell L, Sherins RJ. The number of embryos available for transfer predicts successful pregnancy outcome in women over 39 years with normal ovarian hormonal reserve testing. J Assist Reprod Genet 2001;18(10): 551-556

22 van Loendersloot L, Repping S, Bossuyt PM, van der Veen F, van Wely M. Prediction models in in vitro fertilization; where are we? A mini review. J Adv Res 2014;5(3):295-301

23 Devreker F, Pogonici E, De Maertelaer V, Revelard P, Van den Bergh $M$, Englert Y. Selection of good embryos for transfer depends on embryo cohort size: implications for the 'mild ovarian stimulation' debate. Hum Reprod 1999;14(12):3002-3008

24 Salha O, Dada T, Levett S, Allgar V, Sharma V. The influence of supernumerary embryos on the clinical outcome of IVF cycles. J Assist Reprod Genet 2000;17(6):335-343 